\title{
Extracting Maximum Power Optimization in Wind Turbine Using Neuro Fuzzy Logic Control.
}

\author{
I. ARUL ${ }^{1}$, DR.M.KARTHIKEYAN ${ }^{2}$, DR.N.KRISHNAN ${ }^{3,}$ K. MANIRAJ $^{4}$ \\ Research Scholar, Centre for Information Technology and Engineering, M.S University, Tirunelveli, India \\ Prof \& Head, Department of ECE, Tamilnadu College of Engineering, Coimbatore, India. \\ Prof. \& Head, Centre for Information Technology and Engineering, M.S University, Tirunelveli, India. \\ Head, Dept of InfoTech, M.S.P.V.L Polytechnic College Pavoorchatram, Tirunelvei, India.
}

\begin{abstract}
One of the most consistent and reliable renewable energy resources among the power generations is the Wind Energy. In India, the total installed capacity of wind power generation capacity goes around 14,000 $M W$ per year according to ministry of new and renewable energy, India and total installed capacity of wind energy is estimated to be more than $160 \mathrm{GW}$ [WWEA] all around the world. TamilNadu has an installation of wind energy around 6,696 MW, which is 41 per cent that of the country.

This paper presents an advanced prediction system that integrates models based on fuzzy-neural networks. The main objective of this paper is to fully control the wind turbine system with induction generator to maximize the power generation. The output power of a wind turbine is calculated. The system has been optimized for operating around $15 \mathrm{~m} / \mathrm{s}$, and though the wind power continues to increase above this point.

The advanced method is to introduce the new ability of estimating variable speed control. The neuro fuzzy controller makes the wind turbine speed to be tuned fine until it gets the error free output which the user need. In this paper, neural networks based controller is used in a narrative approach to solve the problem of tuning a fuzzy logic controller. The membership function of neuro fuzzy logic follows the neural network learning techniques to tune the membership function.

By 2030, wind energy will be the most cost-efficient energy resources on the market. On the other hand, with the growing demand for green electricity worldwide today, the turbine costs raises rapidly. Also the competition for supplying ever green power to the grid, the wind farm operators have to improve their existing power output. In this, we predict the extraction of power through controller based techniques. The scope includes the simulation study, implementation of Neuro-fuzzy logic controller using MATLAB simulator.
\end{abstract}

Keywords: Wind energy, Neuro-Fuzzy Logic, Variable speed induction generator, DFIG, Pitch control.

\section{Introduction}

The aim of neuro- fuzzy controller is to establish maximum power delivery to the grid from available wind power. Nowadays doubly fed induction generator system (DFIG) is used to control the excitation level and generator torque. In order to extract the maximum power optimization, the variation of the wind speed is controlled by the pitch angle of the wind turbine. The effectiveness of the proposed neuro fuzzy controllers are verified under the MATLAB simulation.

In this paper we present a neuro fuzzy controlled maximum power point tracking system suitable for the induction generator operating at variable speeds. The effectiveness of the proposed control scheme is validated through computer simulations under varying wind speeds.

Using neuro fuzzy control, we can produce controller outputs more reliable because the effect of other parameters such as noise and events due to wide range of control region and online changing of the controller parameters can be considered [1]. More over without the need of a detailed mathematical model of the system and just using the knowledge of the total operation and behavior of system, tuning of parameters can be done more easily [1].

The aim of the project is to control the maximum wind generation system and maximum efficiency optimization approach. The wind generation system is highly non-linear process since it is involved power electronic equipment. So the non-linear controller is necessary for controlling non-linear process. So we are using intelligent controller.

The combination of fuzzy system and neural network allows the increase computational efficiency of the software products. Neuro-fuzzy system combines the learning capabilities of neural networks with the linguistic rule interpretation of fuzzy inference systems [13]. In the paper neuro-fuzzy structure is applied to solve electricity consumption prediction problem. 
Extracting Maximum Power Optimization In Wind Turbine Using Neuro Fuzzy Logic Control.

\subsection{Neuro Fuzzy Controller}

A block diagram of the neuro fuzzy-controlled wind-powered generating system is shown in Fig. 1.1 it is assumed that the turbine blades have a fixed pitch angle. Fuzzy control system is used to generate the speed to extract the optimum power generation. The proposed fuzzy controller generates the optimum speed command, which is used to regulate the input current of the $\mathrm{AC}$ to DC converter. The output is inverted at fixed frequency.

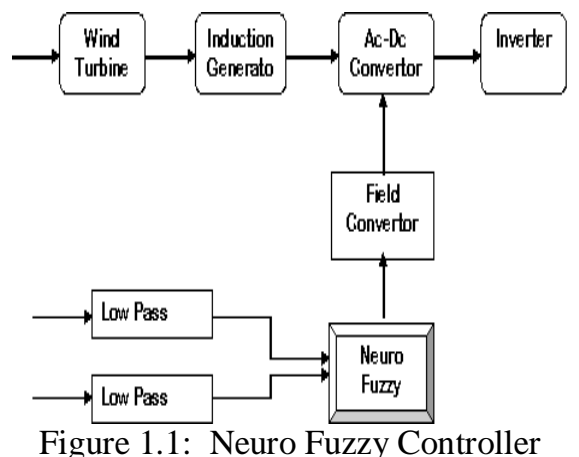

\subsection{Pitch Control}

Figure 1.1: Neuro Fuzzy Controller

To produce a maximum energy, the blade angle must be tuned with wind straightforward using pitch angle control of wind turbine blades. It is worth noticing that we can use this characteristic in abnormal conditions such as grid faults to protect generator from over speeding. In two different cases, an increasing rotor speed may be occurred; a wind speed as input power and an abnormal case due to a fault existence. These must be distinguished first, before a control takes place. When the output terminal voltage falls under 0.9 p.u and the rotor speed is increased, it means a fault is happened.

Linearized system equations

If the system equations are linear (or have been Linearized), the techniques of linear system analysis are used to study dynamic behavior. The most common method is to simulate each component by its transfer function. The various transfer function blocks are connected to represent the system under study. The system performance may then be analyzed by such methods as root-locus plots, frequency domain analysis (Nyquist criteria), and Routh's criterion.

ANFIS structure for blade pitch angle control of VSWPGS is given in Figure below.

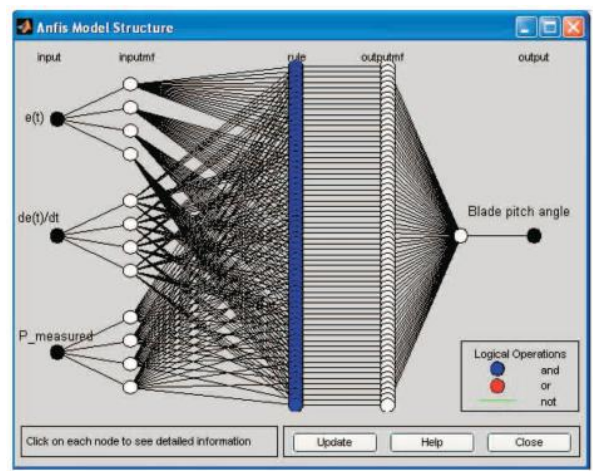

Figure 1.2: ANFIS Structure

\subsection{Doubly fed Induction Generator}

A doubly fed induction generator is coupled to the grid through power electronic converter connected between the rotor windings of DFIG and the grid. The voltage drop at the terminals results in large, oscillatory currents in the stator winding of DFIG. Because of magnetic coupling between stator and rotor winding, these currents will also flow through the converter and high current can cause its thermal breakdown.

Whenever the fault occurs, the rotor winding are short circuited by a set of resistors. This short circuit current will flow through this crow bar instead of the converter. In this paper, we analyze the behavior of a crow bar protected DFIG. Based upon this, approximate equations are derived to determine the short circuit current contribution of the wind turbine.

To construct a variable speed constant frequency system, an induction generator is considered attractive due to its flexible rotor speed characteristic with respect to the constant stator frequency [11]. One of the solutions is to expand the speed range and reduce the slip power losses simultaneously. DFIG is to doubly excite the stator and rotor windings. The power converters generate the majority of the slip power in the rotor circuit. 


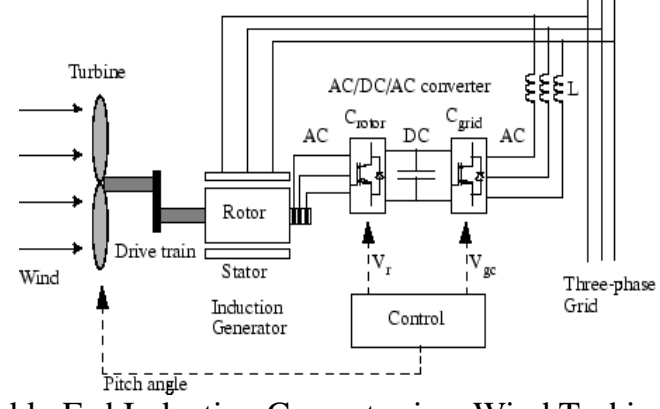

Figure 1.3: Doubly Fed Induction Generator in a Wind Turbine model (DFIG).

\section{Back Propagation Learning Algorithm}

Based on this algorithm, the networks learns a distributed associative map between the input and output layers. The BPL Algorithm makes this process to calculate the weights during the learning phase of the network. Normally it is difficult to calculate the weights within multilayer perceptions. The weights in the hidden layers are calculated in an efficient way, which results in least (zero) output error. The weights are updated by calculating the error output generated during the process. At the output layer the error can be measured to the expected target output. However at the hidden layers, there is no any direct observation method for calculating the error output generated. Hence we require special technique for calculating the error, which is our ultimate goal.

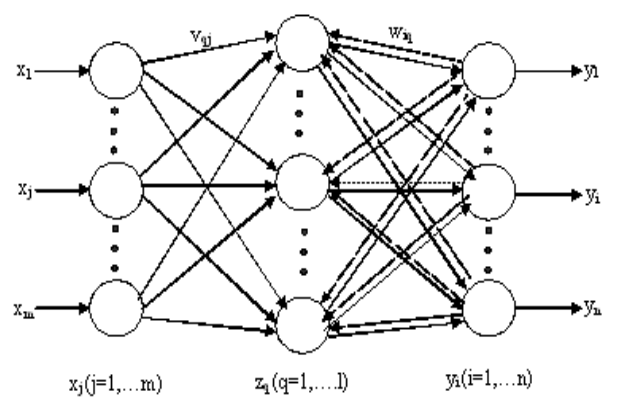

Figure 2.1: Neuro-model

For a given input - output pair $\left(\mathrm{x}_{\mathrm{k}}, \mathrm{d}_{\mathrm{k}}\right)$ the back - propagation algorithm performs two phase of data flow. First, the input pattern $a_{x}$ ' is propagated from the input layer to the output layer. Finally it produces an actual output $\mathrm{y}_{\mathrm{k}}$.

\section{Proposed Simulation Model Of Wind Turbine}

In this wind power production system, variations in frequency, output voltage and drawn power curves of the system are obtained individually by means of the simulation study without any controller element. Different power demands of consumers are expressed as $250 \mathrm{~kW}, 500$ and $600 \mathrm{~kW}$. The controller element is put into operation depending on variations in electrical magnitudes of the wind power production system in such loading situations. Amplitude of the voltage obtained from the system must be within permitted limits whatever the electric energy production system is used. It is known that frequency of the system in other important magnitude is $60 \mathrm{~Hz}$ in Turkey operating conditions. Now the system frequency in electric energy production stations is tried to be kept in $50 \mathrm{~Hz}$ value. To obtain high quality power, the magnitude values of frequency and voltage must be kept in the desired range. The quality of obtained power may be brought to desired level by decreasing the undesired harmonic currents and voltages to minimum level. By considering the situation the wind power production system will operate with the network, the frequency and voltage value is adjusted according to the frequency and voltage values of the network.

. Induction Generator

\begin{tabular}{|l|l|}
\hline Parameter & Unit \\
\hline Stator Resistance $\quad$ R1 & $0.0045 \Omega$ \\
\hline Stator Leakage Reactance X1 & $0.0513 \Omega$ \\
\hline Magnetizing Reactance $\quad$ Xh & $2.2633 \Omega$ \\
\hline Rotor Reactance (referred to Stator) $\quad$ X'2 $0.066 \Omega$ \\
\hline Rotor Resistance (referred to Stator) R'20.004 $\Omega$ \\
\hline Magnetizing Resistance Rfe $\quad 83.3 \Omega$ \\
\hline \multicolumn{2}{|c|}{ Table 1. Induction generator parameters } \\
\hline
\end{tabular}


A 3-phase doubly induction generator with a nominal power of 1.66MVA, $575 \mathrm{~V}(\varphi-\varphi), 60 \mathrm{HZ}$ is used for the power optimization system. The above table shows the parameters and unit values which is operated in the induction generator.

\subsection{Wind and Wind Turbine Model}

\section{Experimental Setup And Results}

This block implements a variable pitch wind turbine model. The performance co-efficient $\mathrm{Cp}$ of the turbine is the mechanical output power of the turbine divided with power and a function of wind speed, rotational speed and pitch angle. Cp reaches the maximum value of zero beta. This result in the torque applied to the induction generator shaft for per unit of the generator ratings. The turbine inertia must be added to the generator inertia.

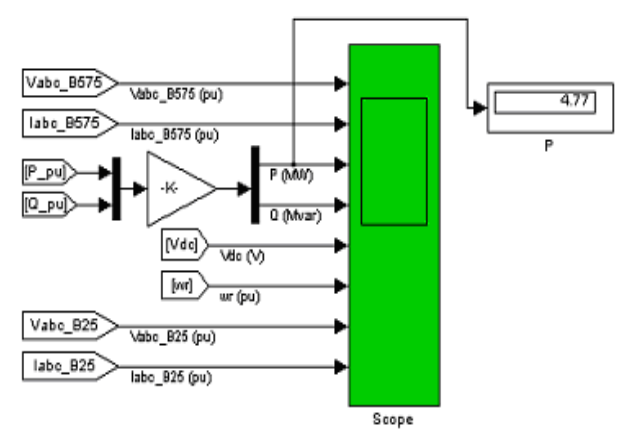

Figure 4.1: Wind Turbine Model.

In the block diagram of the wind power production system given in Figure 4.1, the output of the wind speed model is defined as the kinetic energy or speed of wind. The wind speed is converted to mechanic power or moment by the wind turbine model. The obtained mechanic power or moment is the first input of the mechanic system (of drive system). The other second input of the mechanic system is the proportional speed of the asynchronous generator. Inputs of the asynchronous generator are: mechanical energy obtained from the wind turbine, voltage and frequency magnitudes at ends of the network or load.

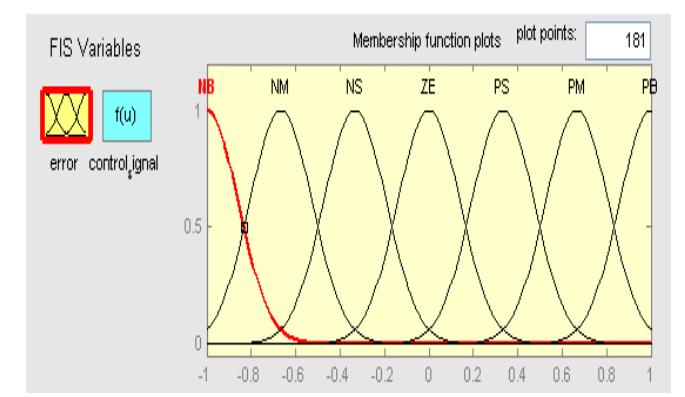

Figure 4.2 : Membership Function

Outputs of the asynchronous generator are the active and reactive power values required for the network or load. In the wind power production systems that operate in isolated manner from electric networks, voltage and frequency of the asynchronous generator can be expressed as output magnitudes.

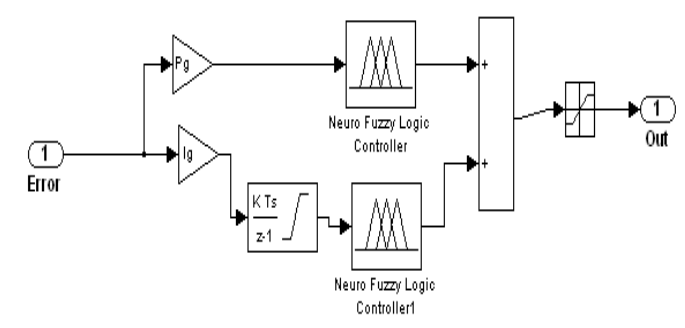

Figure 4.3: Neuro Fuzzy Architectural Design 


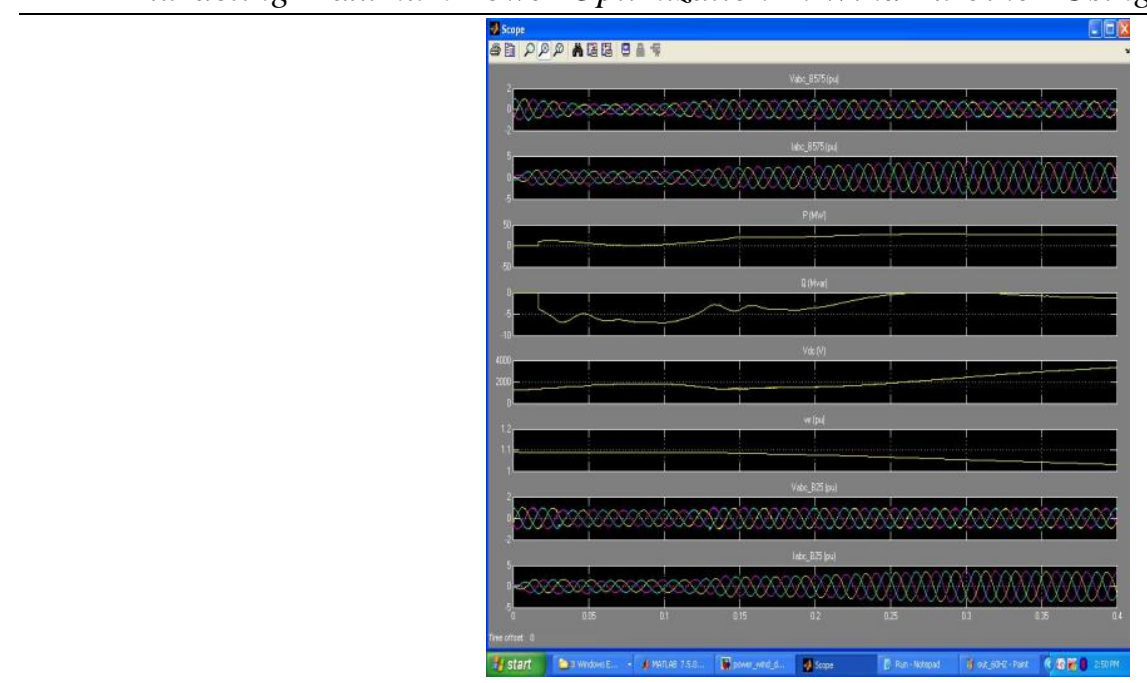

Figure 4.4: Measured Current \& Voltage in Matlab simulation

\section{Conclusion}

In this work, a neuro fuzzy control scheme for extracting maximum power from a variable speed wind turbine has been presented. It has been shown that the turbine power output depends nonlinearly on its angular speed and the wind speed. Neuro-Fuzzy control is well suited for searching the optimum speed at which the turbine should operate under varying wind conditions. The performance of the proposed scheme has been simulated under abrupt changes in wind. It has been shown that the Neuro-fuzzy controller adjusts the angular speed so that the turbine power coefficient converges to its maximum value in the steady state. The methodology used was simple and show step by step all the adjustments and calculations necessary for a satisfactory operation of the system.

For terminal voltage and frequency control of the variable speed wind power generation system, ANFIS is designed and is used in simulation block diagram of VSWPGS under the Matlab/Simulink program. To obtain in high quality power from the wind power generation system (VSWPGS), the effective value of output voltage must be at 400 volt and frequency in $50 \mathrm{~Hz}$ operational limit values. For this purpose, power limitation or speed control of the variable speed wind turbine is performed by means of controlling of turbine blade pitch angle. For controlling of blade pitch angle, the conventional neuro-fuzzy controller is used separately.

As a result of controlling of the wind turbine blade pitch angle, it is determined from the simulation results that the output electrical magnitudes of VSWPGS (voltage, current, frequency and power) reach to desirable values within 1.5 seconds. When the simulation results are examined, it is observed that continuous situation error is close to zero in continuous operation. However, as the load of consumers fed from VSWPGS differs in every hour of a day, coefficients of the conventional controller must be readjusted depending on changing load situations. For this reason, in case of changing consumer load situations, the turbine blade pitch angle is adaptively adjusted to keep the terminal voltage and frequency within permitted tolerance values.

When simulation curves of electrical output magnitudes obtained as a result of controlling of blade pitch angle of VSWPGS with ANFIS are examined, it is seen that operational performance of the system is within a very good value. Meanwhile, no problem about compatibility of ANFIS with VSWPGS has been experienced.

\section{Acknowledgements}

The authors would like to acknowledge the support provided by Dr. M.Karthikeyan for the research process. This work has been made possible thanks to the generosity of Dr. N.Krishnan H.O.D., Department of Centre for Information Technology and Computer Engineering, of Manonmaniam Sundaranar University, Tirunelveli under the Ph.D Scholarship.

\section{References}

[1] H. Karimi-Davijani,1 A. Sheikholeslami, H. Livani and M. Karimi-Davijani," Fuzzy Logic Control of Doubly Fed Induction Generator Wind Turbine”, World Applied Sciences Journal 6 (4): 499-508, 2009, IDOSI Publications, 2009.

[2] B.Chitti Babu , K.B.Mohanty "Doubly-Fed Induction Generator for Variable Speed Wind Energy Conversion Systems- Modeling \& Simulation "International Journal of Computer and Electrical Engineering, February, 2010.

[3] Quincy Wang, and Liuchen Chang, “An Intelligent Maximum Power Extraction Algorithm for Inverter-Based Variable Speed Wind Turbine Systems” IEEE Transactions on Power Electronics, September 2004.

4] Whei-Min Lin, Chih-Ming Hong, and Chiung-Hsing Chen "Neural-Network-Based MPPT Control of a Stand-Alone Hybrid Power Generation System" IEEE Transactions on Power Electronics, December 2011. 
[5] Pengwei Sun, Chuang Liu, Jih-Sheng Lai, Fellow, IEEE, and Chien-Liang Chen, "Grid-Tie Control of Cascade Dual-Buck Inverter with Wide-Range Power Flow Capability for Renewable Energy Applications" IEEE Transactions on Power Electronics, April 2012.

[6] Shuhui Li, Senior Member, IEEE, Timothy A. Haskew, Senior Member, IEEE, Richard P. Swatloski, and William Gathings "Optimal and Direct-Current Vector Control of Direct-Driven PMSG Wind Turbines "IEEE Transactions On Power Electronics, May 2012.

[7] Yu-Lin Juan, Member, IEEE “An Integrated-Controlled AC/DC Interface for Microscale Wind Power Generation Systems” IEEE Transactions On Power Electronics, May 2011.

[8] Xibo Yuan, Fei (Fred) Wang, Dushan Boroyevich, Fellow, Yongdong Li and Rolando Burgos, Member, IEEE "DC-link Voltage Control of a Full Power Converter for Wind Generator Operating in Weak-Grid Systems" IEEE Transactions On Power Electronics, September 2009.

[9] Wei Qiao, Wei Zhou, José M. Aller, and Ronald G. Harley, Fellow, IEEE "Wind Speed Estimation Based Sensorless Output Maximization Control for a Wind Turbine Driving a DFIG” IEEE transactions on power electronics, may 2008.

[10] Yuanye Xia, Khaled H. Ahmed, and Barry W. Williams "A New Maximum Power Point Tracking Technique for Permanent Magnet Synchronous Generator Based Wind Energy Conversion System" IEEE transactions on power Electronics, vol. 26, no. 12, december 2011.

[11] Kostyantyn Protsenko and Dewei Xu "Modeling and Control of Brushless Doubly-Fed Induction Generators in Wind Energy Applications" Department of Electrical and Computer Engineering Ryerson University, canada.

[12] Jon Are Suul, Marta Molinas, Member, IEEE, and Tore Undeland, Fellow, IEEE "STATCOM-Based Indirect Torque Control of Induction Machines During Voltage Recovery After Grid Faults" IEEE Transactions On Power Electronics, Vol. 25, No. 5, May 2010.

[13] Rahib Abiyev, Vasif H. Abiyev, and Cemal Ardil," Electricity Consumption Prediction Model using Neuro-Fuzzy System”, World Academy of Science, Engineering and Technology 82005.

[14] D.Aouzellag, K.Ghedamsi E.M.Berkouk “ Power Control of a Variable Speed Wind Turbine Driving an DFIG” Electrical engineering Department, A.Mira University, Bejaïa, Algeria.

[15] Y"uksel O־GUZ1, 'Irfan GUNEY2 "Adaptive neuro-fuzzy inference system to improve the power quality of variable-speed wind power generation system” Turk J Elec Eng \& Comp Sci, Vol.18, No.4, 2010,_c TU“BI TAK.

[16] Evgenije Adzic*, Zoran Ivanovic*, Milan Adzic**, Vladimir Katic "Maximum Power Search in Wind Turbine Based on Fuzzy Logic Control" Acta Polytechnica Hungarica Vol. 6, No. 1, 2009.

[17] Marcelo Godoy Sim̃oes, Member, IEEE, Bimal K. Bose, Life Fellow, IEEE, and Ronald J. Spiegel, Member, IEEE, "Design and Performance Evaluation of a Fuzzy-Logic-Based Variable-Speed Wind Generation System", IEEE Transactions On Industry Applications, Vol. 33, No. 4, July/August 1997.

[18] H. Karimi-Davijani,1A. Sheikholeslami, H. Livani and M. Karimi-Davijani," Fuzzy Logic Control of Doubly Fed Induction Generator Wind Turbine", World Applied Sciences Journal 6 (4): 499-508, 2009, IDOSI Publications, 2009. 